\title{
Influência da irrigação com água salina na cultura do girassol ${ }^{1}$
}

\author{
Influence of irrigation with saline water on sunflower
}

\author{
Francisco Alexandre de Morais ${ }^{2 *}$, Marcelo Tavares Gurgel ${ }^{3}$, Fábio Henrique Tavares de Oliveira ${ }^{3}$ e Andygley \\ Fernandes Mota ${ }^{4}$
}

\begin{abstract}
Resumo - O presente experimento foi realizado com o objetivo de avaliar a influência da irrigação com água salina no crescimento e na produção de girassol (híbrido H251), além de monitorar a evolução de alguns atributos químicos do solo ao longo do ciclo da cultura. $\mathrm{O}$ delineamento experimental foi em blocos casualizados com seis tratamentos e cinco repetições. Os tratamentos consistiram de seis diferentes estratégias de irrigação, sendo cinco delas com utilização de água salina. As avaliações de crescimento (altura de planta, diâmetro de caule e número de folhas) foram realizadas aos 20;40;60;80;100 dias após semeadura (DAS). Aos 100 DAS foi realizada a colheita, ocasião em que se mediu o diâmetro de capítulo, sendo determinados posteriormente o peso de 1000 aquênios e a produtividade de aquênios. As coletas de solo foram realizadas concomitantemente às avaliações de crescimento, nas camadas 0-0,10;0,10-0,30;0,30-0,50 m. Os atributos químicos do solo avaliados foram $\mathrm{Na}^{+}, \mathrm{CE}$ e $\mathrm{pH}$, além das relações $\mathrm{Na}^{+} / \mathrm{Ca}^{2+} \mathrm{e} \mathrm{Na}^{+} / \mathrm{Mg}^{2+}$. A cultura do girassol mostrou-se tolerante à salinidade da água de irrigação, indicando que ela pode ser irrigada com água de CE de até 3,53 dS m-1 durante todo o ciclo. Entretanto, quando se utilizar água de média ou alta $\mathrm{CE}$, é necessária a adoção de práticas de controle da salinização/sodificação do solo. A tolerância do girassol à salinidade não dependeu da fase de desenvolvimento. Em geral, os atributos químicos do solo aumentaram e estabilizaram a partir da metade do ciclo.
\end{abstract}

Palavras-chave - Helianthus annuus L.. Salinidade do solo. Manejo da irrigação.

\begin{abstract}
This experiment was made to evaluate the influence of the irrigation with saline water on growth and production of sunflower (híbrido H251), besides monitoring the evolution of some chemical attributes of the soil along its cycle. The experimental design used was the randomized blocks with six treatments and five replications. The treatments consisted of six different irrigation strategies, five of them with use of saline water. The growth evaluations (plant height, stem diameter and leaf number) were made at 20;40;60;80;100 days after sowing (DAS). The harvest occurred at 100 DAS, then the capitulum diameter was measured and the weight of 1000 achenes, as well as its productivity, were determined. The soil samples were collected on the same dates of the growth evaluations at the layers of $0-0.10 ; 0.10-0.30 ; 0.30-0.50 \mathrm{~m}$. The evaluated soil attributes were $\mathrm{Na}^{+}, \mathrm{EC}$ and $\mathrm{pH}$, besides of the ratios $\mathrm{Na}^{+} / \mathrm{Ca}^{2+}$ and $\mathrm{Na}^{+} / \mathrm{Mg}^{2+}$. The sunflower appeared to be tolerant to the salinity of the irrigation water, what means it could be cultivated normally and still have a good production even when the water EC reaches up to $3.53 \mathrm{dS} \mathrm{m}^{-1}$. However, when using a medium/high EC water, it's needed to adopt some practices to control the salinization/sodification of the soil. The tolerance of the sunflower to salinity was not dependent of the development phase. Overall, the chemical attributes of the soil increased and stabilized from the middle of the cycle on.
\end{abstract}

Key words - Helianthus annuus L.. Soil salinity. Irrigation management.

\footnotetext{
* Autor para correspondência

${ }^{1}$ Recebido para publicação em 31/08/2010; aprovado em 31/01/2011

Trabalho submetido e selecionado no primeiro Simpósio Brasileiro de Salinidade realizado de 12-15/10/2010 em Fortaleza, Ceará, Brasil; Parte da

Monografia de Graduação do primeiro autor apresentada à Universidade Federal Rural do Semi-Árido, pesquisa financiada pelo CNPq/INCTSal

${ }^{2}$ Bolsista do INCTSal/CNPq, graduando em Agronomia/UFERSA, Mossoró-RN, Brasil, 59.625-900, morais@scientist.com

${ }_{3}^{3}$ Departamento de Ciências Ambientais e Tecnológicas, DCAT/UFERSA, Mossoró-RN, Brasil, 59.625-900, marcelo.tavares@ufersa.edu.br, fabio@ufersa.edu.br

${ }^{4}$ Graduando em Agronomia/UFERSA, Mossoró-RN, Brasil, 59.625-900, andygley@mail.com
} 


\section{Introdução}

O girassol (Helianthus annuus L.) é uma dicotiledônea anual e originária da América do Norte (ZOBIOLE et al., 2010). No Brasil o seu cultivo ocupa uma área de aproximadamente 67600 ha, concentrada principalmente na região Centro-Oeste (48800 ha) (CONAB, 2010). Essa espécie apresenta características desejáveis sob o ponto de vista agronômico, como ciclo curto, elevada qualidade e bom rendimento em óleo. Com o incentivo do Governo Federal em utilizar o biodiesel na matriz energética nacional, a cultura do girassol representa uma das oleaginosas mais promissoras para a produção de biocombustíveis (SILVA et al., 2007).

Além disso, devido às características de resistência à seca, ao frio e ao calor, o girassol apresenta ampla adaptabilidade, proporcionando perspectivas para a expansão de sua área cultivada em diversas regiões do Brasil. No Estado do Rio Grande do Norte a produção de girassol tem se destacado nos últimos anos (CONAB, 2010), principalmente na região Oeste - onde se localiza o agropolo Mossoró-Assu.

Essa região é banhada por duas das maiores bacias hidrográficas do Estado - Rio Apodi-Mossoró e Rio Piranhas-Açu - e ainda possui grandes volumes de água subterrânea nos aquíferos Calcário Jandaíra (água de média a alta salinidade) e Arenito Açu (água de baixa salinidade). Essa abundância de água permite a prática da irrigação, mas a falta de manejo adequado, principalmente das águas salinas, tem levado à salinização de alguns solos.

Algumas estratégias podem ser usadas para minimizar os impactos negativos do aproveitamento de água salina na irrigação, entre elas: escolha de espécies ou cultivares mais tolerantes, utilização dessas fontes de água nos estádios de maior tolerância das culturas, mistura de águas de diferentes qualidades, uso cíclico de fontes de água com diferentes concentrações salinas, além de diversas outras práticas visando à obtenção de boa produção vegetal com controle da salinização/sodificação do solo (LACERDA et al., 2009).

A salinidade é um dos principais fatores ambientais limitantes ao crescimento e produtividade das culturas (LV et al., 2008), uma vez que as altas concentrações de sais no solo, além de reduzir o seu potencial hídrico, podem provocar efeitos tóxicos nas plantas, causando distúrbios funcionais e injúrias no metabolismo (SILVA E.N. et al., 2009).

Os efeitos negativos da irrigação com água salina em oleaginosas têm sido observados por vários autores na literatura científica nacional (BLANCO et al., 2007; CORREIA et al., 2009; SILVA et al., 2008; SILVA E.N. et al., 2009), inclusive na cultura do girassol (NOBRE et al., 2010; SILVA T.G.F. et al., 2009). Apesar disso, Katerji et al. (2000) classificaram o girassol como tolerante à salinidade. Entretanto, Ashraf e Tufail (1995) verificaram que há grande variação de tolerância à salinidade em genótipos de girassol.

Diante da ausência de informações, em condições de campo na região Nordeste, acerca da melhor estratégia de irrigação para minimizar os impactos negativos do uso de água salina na cultura do girassol, objetivou-se com esse estudo: avaliar o crescimento e a produção de girassol (híbrido H251) irrigado com água salina de acordo com a fase de desenvolvimento; identificar o(s) estádio(s) de maior tolerância da cultura à salinidade; e monitorar a evolução de alguns atributos químicos do solo ao longo do ciclo.

\section{Material e métodos}

O experimento foi conduzido sob condições de campo, durante o período 01/10/2009 a 09/01/2010, na Fazenda Experimental Rafael Fernandes, pertencente à Universidade Federal Rural do Semi-Árido (UFERSA), no Município de Mossoró-RN, com localização geográfica definida pelas coordenadas $5^{\circ} 11^{\prime}$ de latitude sul e $37^{\circ} 21^{\prime}$ de longitude oeste, com altitude de $18 \mathrm{~m}$. O solo da área experimental é classificado como Argissolo Vermelho-Amarelo de textura francoarenosa (EMBRAPA, 1999). Na Tabela 1 se encontra a caracterização química do solo antes do experimento.

O clima da região, segundo Thornthwaite, é semi-árido, com pouco ou nenhum excesso de água;

Tabela 1 - Caracterização química do solo antes do experimento

\begin{tabular}{|c|c|c|c|c|c|c|c|c|c|c|c|c|c|}
\hline \multirow{2}{*}{ Camadas } & & & $\mathrm{Na}^{+}$ & $\mathrm{K}^{+}$ & $\mathrm{t}$ & CTC & \multirow{2}{*}{$\frac{\mathrm{P}}{\mathrm{mg} \mathrm{dm^{-3 }}}$} & \multirow{2}{*}{$\frac{\mathrm{pH}}{\left(\mathrm{H}_{2} \mathrm{O}\right)}$} & \multirow{2}{*}{$\frac{\mathrm{CE}}{\mathrm{dS} \mathrm{m}^{-1}}$} & MO & $\mathrm{m}$ & $\mathrm{V}$ & PST \\
\hline & \multicolumn{6}{|c|}{ 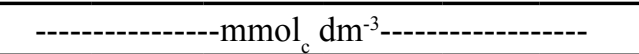 } & & & & \multicolumn{4}{|c|}{ 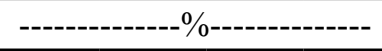 } \\
\hline & 3,0 & 1,0 & & 0381 & & 11,1 & 2,0 & 6,20 & 0,039 & 0,71 & 0 & 40,7 & 1,37 \\
\hline $0,10-0,30 \mathrm{~m}$ & 1,0 & 2,0 & 0,070 & 0,494 & 5,1 & 10,2 & 1,7 & 5,20 & 0,047 & 0,58 & 29,6 & 35,1 & 0,68 \\
\hline $0,30-0,50 \mathrm{~m}$ & 1,0 & 1,0 & 0,017 & 0,522 & 4,5 & 9,1 & 0,7 & 5,02 & 0,047 & 0,54 & 44,1 & 27,8 & 0,19 \\
\hline
\end{tabular}


e de acordo com Köppen, é BSwh', semi-árido muito quente, com uma estação seca, que vai geralmente de junho a janeiro, e uma chuvosa, de fevereiro a maio (CARMO FILHO et al., 1991). Durante a condução do experimento praticamente não choveu na área experimental e a temperatura média foi de aproximadamente $27^{\circ} \mathrm{C}$ (FIG. 1).

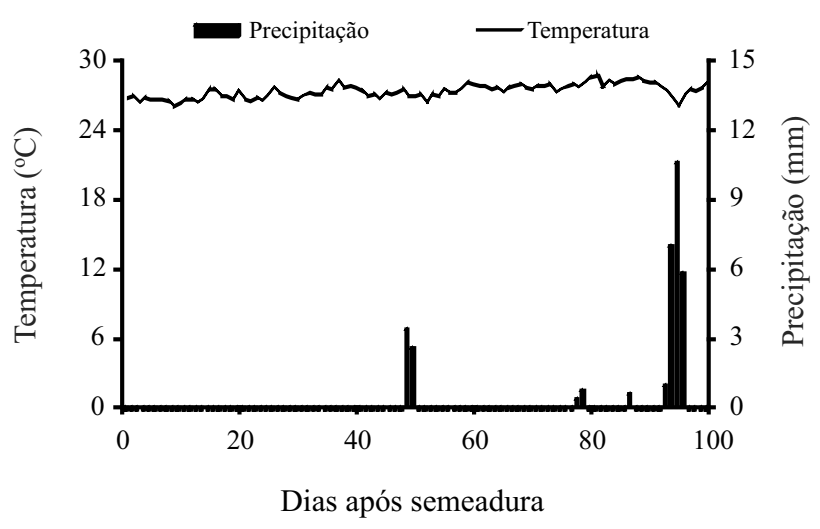

Figura 1 - Dados diários de temperatura e precipitação pluvial registrados durante a condução do experimento em campo

O delineamento experimental foi em blocos casualizados com seis tratamentos e cinco repetições, totalizando trinta parcelas. Os tratamentos consistiram de seis diferentes estratégias de irrigação, sendo cinco delas com utilização de água salina, conforme a Tabela 2.

Tabela 2 - Tratamentos resultantes da combinação entre fases de desenvolvimento do girassol e águas de diferentes salinidades

\begin{tabular}{|c|c|c|c|}
\hline \multirow{2}{*}{ Tratamentos } & 0 a 45 DAS & $\begin{array}{c}45 \text { a } 90 \\
\text { DAS }\end{array}$ & $\begin{array}{c}90 \text { DAS } \\
\text { até colheita }\end{array}$ \\
\hline & $\begin{array}{c}\text { Fase } \\
\text { vegetativa }\end{array}$ & \multicolumn{2}{|c|}{ Fase reprodutiva } \\
\hline $\mathrm{T} 1$ & S1 & S1 & S1 \\
\hline $\mathrm{T} 2$ & S2 & S2 & $\mathrm{S} 2$ \\
\hline $\mathrm{T} 3$ & $\mathrm{~S} 3$ & S3 & $\mathrm{S} 3$ \\
\hline $\mathrm{T} 4$ & $\mathrm{~S} 1$ & S2 & $\overline{\mathrm{S} 2}$ \\
\hline T5 & S1 & $\mathrm{S} 2$ & S3 \\
\hline T6 & S1 & S3 & S3 \\
\hline
\end{tabular}

DAS - Dias após semeadura; $\mathrm{S} 1-0,55 \mathrm{dS} \mathrm{m}^{-1} ; \mathrm{S} 2(\mathrm{~S} 1+\mathrm{S} 3)-2,16 \mathrm{dS} \mathrm{m}^{-1}$; $\mathrm{S} 3-3,53 \mathrm{dS} \mathrm{m}^{-1}$

As avaliações de crescimento e as coletas de solo foram realizadas aos 20;40;60;80; 100 dias após semeadura (DAS). As amostras de solo foram compostas de 3 pontos a $0,15 \mathrm{~m}$ do gotejador, em forma de triângulo, nas camadas $0-0,10 ; 0,10-0,30 ; 0,30-0,50 \mathrm{~m}$. Cada parcela constou de seis linhas de $7 \mathrm{~m}$ de comprimento e tanto as avaliações de crescimento quanto as coletas de solo foram realizadas nas linhas 2 e 5 . Para as avaliações de crescimento foram escolhidas e identificadas 4 plantas por parcela no início do ciclo, enquanto as coletas de solo foram realizadas nas proximidades de plantas que eram escolhidas aleatoriamente. As linhas 3 e 4 constituíram a área útil $\left(12,6 \mathrm{~m}^{2}\right)$ para a avaliação da produção do girassol e as linhas 1 e 6 foram consideradas bordaduras.

Utilizou-se o híbrido H251. A semeadura foi realizada manualmente no dia 1 de outubro de 2009, em linhas espaçadas de $0,90 \mathrm{~m}$, com duas sementes a cada $0,30 \mathrm{~m}$, fazendo-se o desbaste quinze dias depois, quando se deixou apenas uma planta por cova e aproximadamente 37037 plantas por hectare.

Foi realizada uma fertilização de semeadura e duas de cobertura via fertirrigação. A fertilização de semeadura foi realizada manualmente no dia 25 de setembro de 2009 , aplicando-se, em sulco, uréia, superfosfato simples, cloreto de potássio, ácido bórico, sulfato de zinco e sulfato de cobre nas quantidades 78,$4 ; 1120 ; 162,6 ; 14,8 ; 11,0 ; 5,0$ gramas por parcela, respectivamente. A primeira cobertura foi realizada aos 30 DAS, aplicando-se sulfato de amônio, cloreto de potássio e ácido bórico nas quantidades 352,8; 162,$6 ; 14,8$ gramas por parcela, respectivamente. A segunda cobertura foi realizada aos 53 DAS, aplicando-se sulfato de amônio na quantidade 352,8 gramas por parcela.

O sistema de irrigação adotado foi o de gotejamento, apresentando um coeficiente de uniformidade de distribuição de $93,85 \%$ e vazão de $1,74 \mathrm{~L} \mathrm{~h}^{-1}$. A irrigação foi realizada de modo a repor a evapotranspiração da cultura, estimada para cada fase de desenvolvimento da planta, a partir da evapotranspiração de referência (ETo) pelo método de Penman-Monteith e coeficiente de cultura (Kc).

A água de salinidade baixa (S1) utilizada nas irrigações foi retirada de um poço do aquífero Arenito Açu, a uma profundidade média de $1000 \mathrm{~m}$. A água de salinidade alta (S3) foi preparada mediante a adição, na água $\mathrm{S} 1$, dos sais $\mathrm{NaCl}$, $\mathrm{NaHCO}_{3}, \mathrm{CaCl}_{2} \cdot 2 \mathrm{H}_{2} \mathrm{O}, \mathrm{MgSO}_{4} \cdot 7 \mathrm{H}_{2} \mathrm{O}$ e $\mathrm{KCl}$ nas quantidades 1,$169 ; 0,504 ; 0,441 ; 0,346 ; 0,030 \mathrm{~g} \mathrm{~L}^{-1}$, respectivamente. A proporcionalidade utilizada para $\mathrm{Na}: \mathrm{Ca}: \mathrm{Mg}$ - 7:2:1 - está de acordo com Medeiros (1992). Esses valores são uma aproximação representativa da maioria das fontes de água salina disponível no aquífero Calcário Jandaíra. A água de salinidade média (S2) foi proveniente da mistura de volumes iguais das águas S1 e S3. Foram feitas análises químicas semanalmente das águas utilizadas e os valores médios obtidos ao longo do experimento estão apresentados na Tabela 3. 
Tabela 3 - Caracterização química das águas utilizadas na irrigação

\begin{tabular}{|c|c|c|c|c|c|c|c|c|c|c|c|c|c|}
\hline \multirow{2}{*}{ Águas } & $\mathrm{K}^{+}$ & $\mathrm{Na}^{+}$ & $\mathrm{Ca}^{2+}$ & $\mathrm{Mg}^{2+}$ & $\mathrm{Cl}^{-}$ & $\mathrm{CO}_{3}^{2-}$ & $\mathrm{HCO}_{3}^{-}$ & Cátions & Ânions & \multirow{2}{*}{$\mathrm{pH}$} & \multirow{2}{*}{$\frac{\mathrm{CE}}{\mathrm{dS} \mathrm{m^{-1 }}}$} & \multirow{2}{*}{$\frac{\text { RAS }}{\left(\mathrm{mmol}_{\mathrm{c}} \mathrm{L}^{-1}\right)^{0,5}}$} & \multirow{2}{*}{$\frac{\text { Dureza }}{\mathrm{mg} \mathrm{L}^{-1}}$} \\
\hline & \multicolumn{9}{|c|}{$\mathrm{mmol}_{\mathrm{c}} \mathrm{L}^{-1}$} & & & & \\
\hline S1 & 0,5 & 2,1 & 2,5 & 1,4 & 1,7 & 0,9 & 3,6 & 6,6 & 6,2 & 7,78 & 0,55 & 1,49 & 171,92 \\
\hline S2 & 0,5 & 16,7 & 3,5 & 2,7 & 13,8 & 0,9 & 4,4 & 23,5 & 19,2 & 7,77 & 2,16 & 9,51 & 311,67 \\
\hline S3 & 0,7 & 27,7 & 4,3 & 3,6 & 25,7 & 0,8 & 5,0 & 35,8 & 31,6 & 7,69 & 3,53 & 14,02 & 350,60 \\
\hline
\end{tabular}

As variáveis de crescimento avaliadas foram altura de planta, diâmetro de caule e número de folhas. Já os componentes de produção foram diâmetro de capítulo, peso de 1000 aquênios e produtividade de aquênios. Os atributos químicos do solo foram sódio trocável, $\mathrm{CE}$ e $\mathrm{pH}$, além das relações $\mathrm{Na}^{+} / \mathrm{Ca}^{2+}$ e $\mathrm{Na}^{+} / \mathrm{Mg}^{2+}$. As avaliações dos caracteres agronômicos do girassol foram realizadas conforme metodologia descrita por Castiglioni et al. (1997). As análises de sódio, cálcio e magnésio trocáveis e do $\mathrm{pH}$ foram realizadas conforme metodologia descrita por Silva (2009). A condutividade elétrica foi obtida através da leitura no condutivímetro digital da suspensão solo/água destilada na proporção de 1:2,5 (RICHARDS, 1954).

Os dados das variáveis de crescimento e dos atributos químicos do solo aos 100 DAS, além dos componentes de produção, foram tabulados e submetidos à análise de variância e teste de média (Tukey, $\mathrm{p}<0,05$ ), utilizando-se o software SISVAR (FERREIRA, 2008). Entretanto, antes da condução da análise estatística, foi realizado o teste de Hartley para averiguar a homogeneidade das variâncias (BANZATTO; KRONKA, 1995), com consequente necessidade de transformação de alguns dados. Os valores de $\mathrm{Na}^{+} / \mathrm{Ca}^{2+}, \mathrm{Na}^{+} / \mathrm{Mg}^{2+}$ e CE foram transformados em $\sqrt{x}$ e os de $\mathrm{Na}^{+}$em $\ln (\mathrm{x})$. Não houve necessidade de transformação para as demais variáveis.

\section{Resultados e discussão}

\section{Crescimento e produção de girassol}

O crescimento do girassol não foi influenciado pela irrigação com água salina, independentemente da fase de desenvolvimento da cultura. As variáveis altura de planta, diâmetro de caule e número de folhas apresentaram evolução semelhante ao longo do ciclo para todos os tratamentos (FIG. 2). Além disso, a análise de variância não revelou diferença significativa entre os tratamentos para as variáveis supracitadas no final do ciclo. Também não foi observada diferença significativa para os componentes de produção (TAB. 4 e 5).

A ausência de efeito significativo entre os tratamentos demonstrou que a cultura do girassol tolerou salinidade alta da água de irrigação, indicando que ela pode ser irrigada com água de $\mathrm{CE}$ de até $3,53 \mathrm{dS} \mathrm{m}^{-1}$, durante todo o ciclo (tratamento T3), sem prejuízos ao crescimento das plantas e sem diminuição na produção. Vale salientar que os tratamentos T2 (mistura de águas de diferentes qualidades), T4, T5 e T6 (utilização de água salina apenas em alguns estádios da cultura) mostraram o mesmo desempenho. Esses resultados corroboram as conclusões de Katerji et al. (2000) e Ashraf e Tufail (1995). Em relação ao primeiro estudo, por classificar o girassol como tolerante à salinidade.
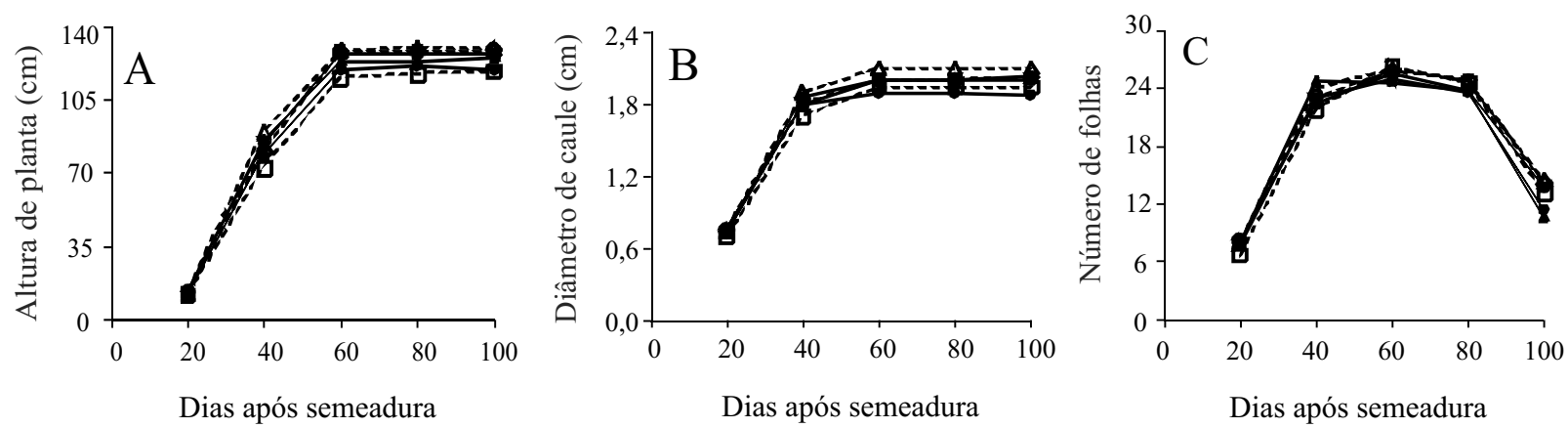

Figura 2 - Evolução das variáveis de crescimento ao longo do ciclo do girassol em função dos tratamentos 
Tabela 4 - Resumo da ANOVA para altura de planta (AP)*, diâmetro de caule (DC)*, número de folhas (NF)*, diâmetro de capítulo (DCAP), peso de 1000 aquênios (PMIL) e produtividade de aquênios (PROD), em função dos tratamentos

\begin{tabular}{cccccccc}
\hline \multirow{2}{*}{ Fonte de variação } & \multirow{2}{*}{ Graus de liberdade } & \multicolumn{5}{c}{ Quadrado médio } \\
\cline { 3 - 8 } & & AP & DC & NF & DCAP & PMIL & PROD \\
\hline Tratamentos & 5 & $101,36^{\text {ns }}$ & $0,030^{\text {ns }}$ & $10,55^{\text {ns }}$ & $1,39^{\text {ns }}$ & $10,18^{\text {ns }}$ & $73821,39^{\text {ns }}$ \\
Bloco & 4 & 27,72 & 0,020 & 3,28 & 2,52 & 28,90 & 58876,34 \\
Resíduo & 20 & 48,65 & 0,036 & 15,93 & 3,10 & 11,68 & 59845,10 \\
\hline C.V. $(\%)$ & - & 5,41 & 9,52 & 31,93 & 10,18 & 4,61 & 14,73 \\
\hline
\end{tabular}

* Valores medidos aos 100 DAS; ${ }^{\text {ns }}$ - Não significativo

Quanto ao segundo, por afirmar que essa tolerância não varia com a fase do ciclo da planta.

Ainda segundo Ashraf e Tufail (1995), esses são os componentes importantes da tolerância do girassol à salinidade: baixa absorção de $\mathrm{Cl}^{-}$, alta de $\mathrm{K}^{+}$, manutenção de alta relação $\mathrm{K}: \mathrm{Na}$ e, possivelmente, o acúmulo de solutos orgânicos, tais como carboidratos e proteínas solúveis, prolina e aminoácidos livres. Nesse sentido, Bhatt e Indirakutty (1973) observaram que a colheita de girassol retirou mais de duas vezes e meia a quantidade de sódio em comparação com o que foi perdido devido a lixiviação. Além disso, os mesmos autores sugerem que consórcio ou rotação com girassol pode reduzir a salinidade do solo e melhorar as suas condições onde estão surgindo problemas de salinidade, especialmente em solos argilosos pesados, com baixa permeabilidade.
Divergindo parcialmente dos resultados do presente estudo, Silva T.G.F. et al. (2009) verificaram que o aumento da $\mathrm{CE}$ da solução nutritiva reduziu significativamente o acúmulo de massa seca total das plantas, das folhas, das hastes, das raízes e dos capítulos, além de afetar a área foliar e a altura das plantas do girassol ornamental. No entanto, não houve diferença significativa entre as salinidade 0,5 e $3,5 \mathrm{dS} \mathrm{m}^{-1}$ em relação ao diâmetro das hastes e dos capítulos.

Semelhantemente, Nobre et al. (2010) observaram que a altura de planta, o diâmetro de caule, a fitomassa seca da parte aérea, o início do florescimento e os diâmetros de capítulo interno e externo de girassol foram afetados linear e negativamente pela salinidade da água de irrigação a partir de $0,5 \mathrm{dS} \mathrm{m}^{-1}$. Entretanto, não houve diferença significativa entre os níveis de salinidade em relação ao número de folhas.

Tabela 5 - Médias de altura de planta (AP)*, diâmetro de caule (DC)*, número de folhas (NF)*, diâmetro de capítulo (DCAP), peso de 1000 aquênios (PMIL) e produtividade de aquênios (PROD), em função dos tratamentos

\begin{tabular}{ccccccc}
\hline \multirow{2}{*}{ Tratamentos } & \multicolumn{5}{c}{ Variáveis } \\
\cline { 2 - 7 } & AP $(\mathrm{cm})$ & DC $(\mathrm{cm})$ & NF & DCAP $(\mathrm{cm})$ & PMIL $(\mathrm{g})$ & ${\text { PROD }\left(\mathrm{kg} \mathrm{ha}^{-1}\right)}^{\circ}$ \\
\hline T1 & $133,30 \mathrm{a}$ & $2,10 \mathrm{a}$ & $14 \mathrm{a}$ & $17,75 \mathrm{a}$ & $75,06 \mathrm{a}$ & $1703,17 \mathrm{a}$ \\
T2 & $122,85 \mathrm{a}$ & $1,94 \mathrm{a}$ & $13 \mathrm{a}$ & $17,25 \mathrm{a}$ & $76,14 \mathrm{a}$ & $1553,97 \mathrm{a}$ \\
T3 & $132,85 \mathrm{a}$ & $2,02 \mathrm{a}$ & $14 \mathrm{a}$ & $18,05 \mathrm{a}$ & $74,59 \mathrm{a}$ & $1884,92 \mathrm{a}$ \\
T4 & $129,45 \mathrm{a}$ & $2,04 \mathrm{a}$ & $10 \mathrm{a}$ & $17,00 \mathrm{a}$ & $74,39 \mathrm{a}$ & $1626,19 \mathrm{a}$ \\
T5 & $131,55 \mathrm{a}$ & $2,00 \mathrm{a}$ & $13 \mathrm{a}$ & $17,10 \mathrm{a}$ & $72,67 \mathrm{a}$ & $1626,19 \mathrm{a}$ \\
T6 & $124,15 \mathrm{a}$ & $1,88 \mathrm{a}$ & $11 \mathrm{a}$ & $16,60 \mathrm{a}$ & $72,42 \mathrm{a}$ & $1571,43 \mathrm{a}$ \\
\hline Média geral & 129,03 & 2,00 & 12 & 17,29 & 74,21 & 1660,98 \\
\hline
\end{tabular}

* Valores medidos aos 100 DAS; Médias seguidas da mesma letra na coluna, não diferem significativamente entre si (Tukey, p $<0,05)$ 
Provavelmente, essas divergências estão relacionadas às diferentes condições em que foram realizados os experimentos. As duas pesquisas citadas anteriormente foram conduzidas em ambiente protegido com as plantas em vasos, em intervalos de tempo inferiores, divergindo ainda quanto aos tipos de solo, métodos e frequências de irrigação, cultivares e níveis de salinidade - ambos utilizaram níveis de salinidade da água de irrigação superiores a $3,53 \mathrm{dS} \mathrm{m}^{-1}$.

\section{Atributos químicos do solo}

Em geral, o $\mathrm{Na}^{+}$, a $\mathrm{CE}$ e o $\mathrm{pH}$, além das relações $\mathrm{Na}^{+} / \mathrm{Ca}^{2+}$ e $\mathrm{Na}^{+} / \mathrm{Mg}^{2+}$, aumentaram e estabilizaram a partir da metade do ciclo do girassol. Esses aumentos foram mais acentuados nos tratamentos que receberam em algum momento as águas S2 e S3, evidenciando a propensão das mesmas em salinizar/sodificar o solo. Apesar disso, não houve influência negativa nas variáveis de crescimento e nos componentes de produção do girassol, conforme já comentado anteriormente. A tendência de estabilização dos atributos supracitados, da metade para o final do ciclo, pode ser explicada pela posição do bulbo úmido onde o solo foi monitorado, pois nessa região ocorre lixiviação vertical e horizontal, levando os sais para a periferia mais distante (DIAS et al., 2004). Provavelmente, a boa permeabilidade do solo proporcionou boa lixiviação dos sais e consequentemente o comportamento uniforme dos cinco atributos químicos do solo nas três camadas avaliadas (FIG. $3 ; 4 ; 5 ; 6 ; 7$ ).

A análise de variância revelou diferença significativa entre os tratamentos para todos os atributos do solo estudados nas três camadas, no final do ciclo (TAB. 6). Na Tabela 7 observa-se que o tratamento T3 apresentou, nas três camadas, as maiores médias de $\mathrm{Na}^{+}$, porém ele não diferiu significativamente dos tratamentos T2, T4, T5 e T6. O mesmo ocorreu com a CE, mas apenas na camada $0-0,10 \mathrm{~m}$. Isso pode ser um indício de que algumas estratégias de irrigação com água salina, como
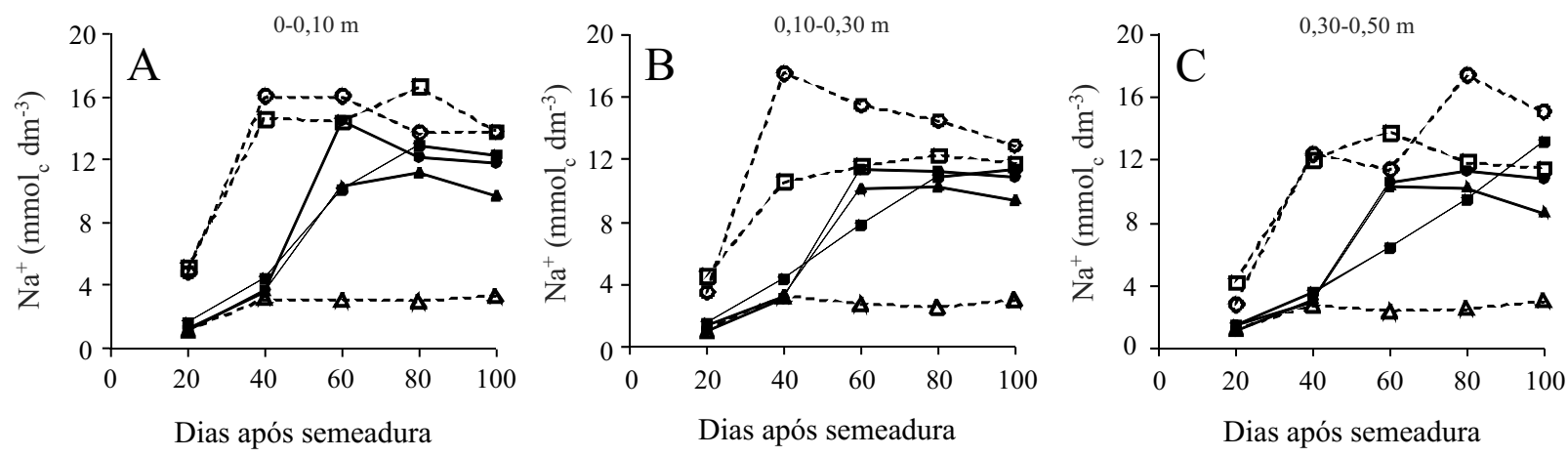

-4- $\mathrm{T} 1$ -

Figura 3 - Evolução do sódio trocável em um Argissolo ao longo do ciclo do girassol em função dos tratamentos em cada camada
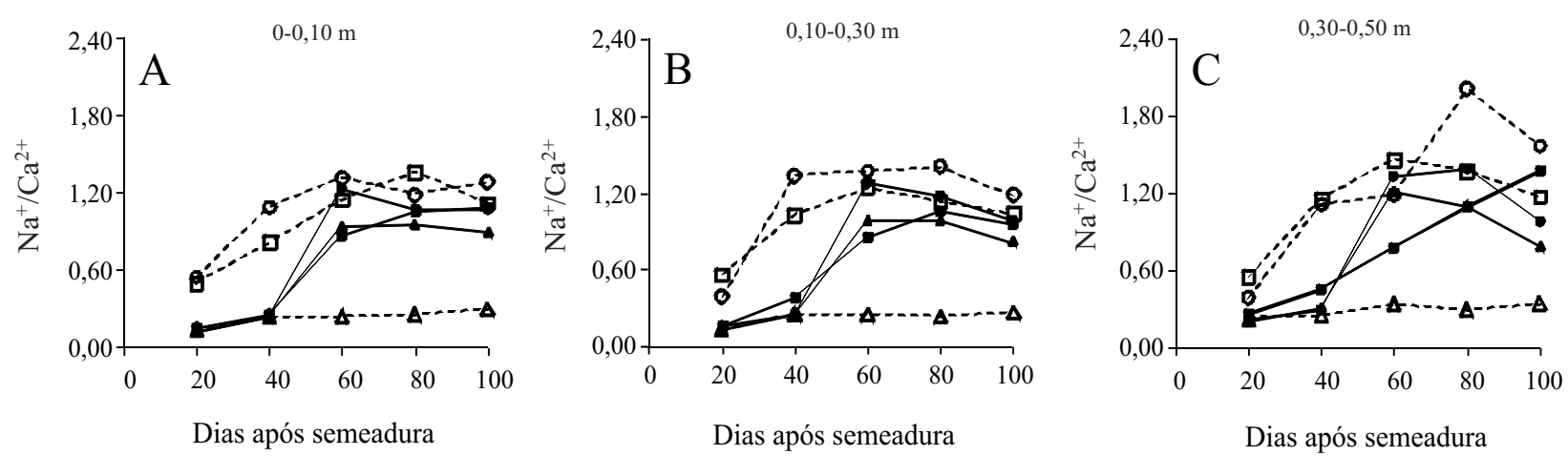

- - - - T1

Figura 4 - Evolução da relação $\mathrm{Na}^{+} / \mathrm{Ca}^{2+}$ em um Argissolo ao longo do ciclo do girassol em função dos tratamentos em cada camada 

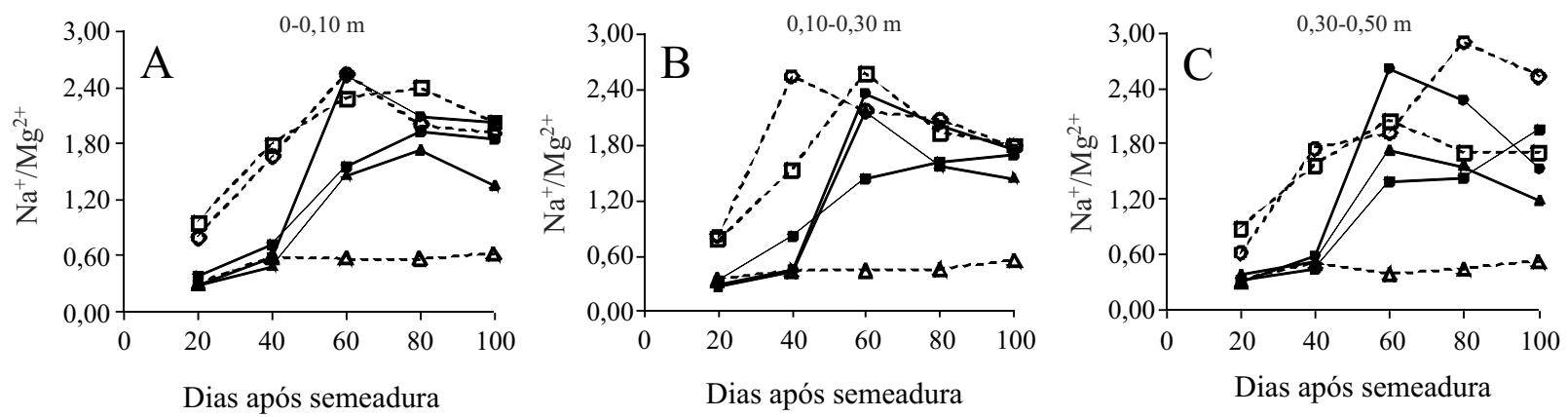

- - - - $\mathrm{T} 1 \quad$ -

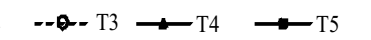

$\rightarrow-\mathrm{T} 6$

Figura 5 - Evolução da relação $\mathrm{Na}^{+} / \mathrm{Mg}^{2+}$ em um Argissolo ao longo do ciclo do girassol em função dos tratamentos em cada camada
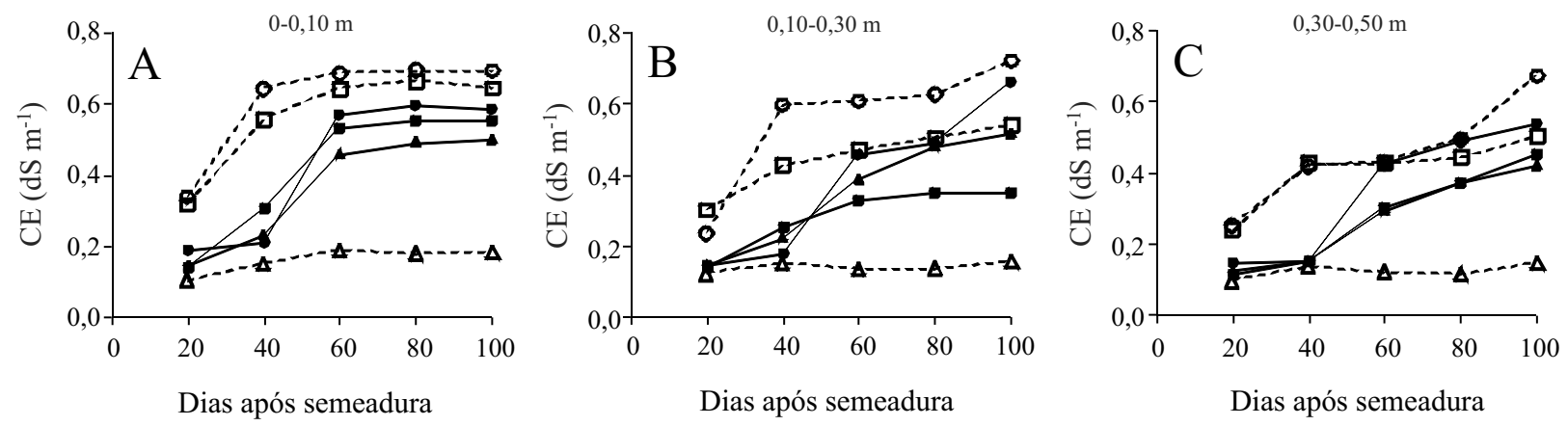

Figura 6 - Evolução da condutividade elétrica em um Argissolo ao longo do ciclo do girassol em função dos tratamentos em cada camada
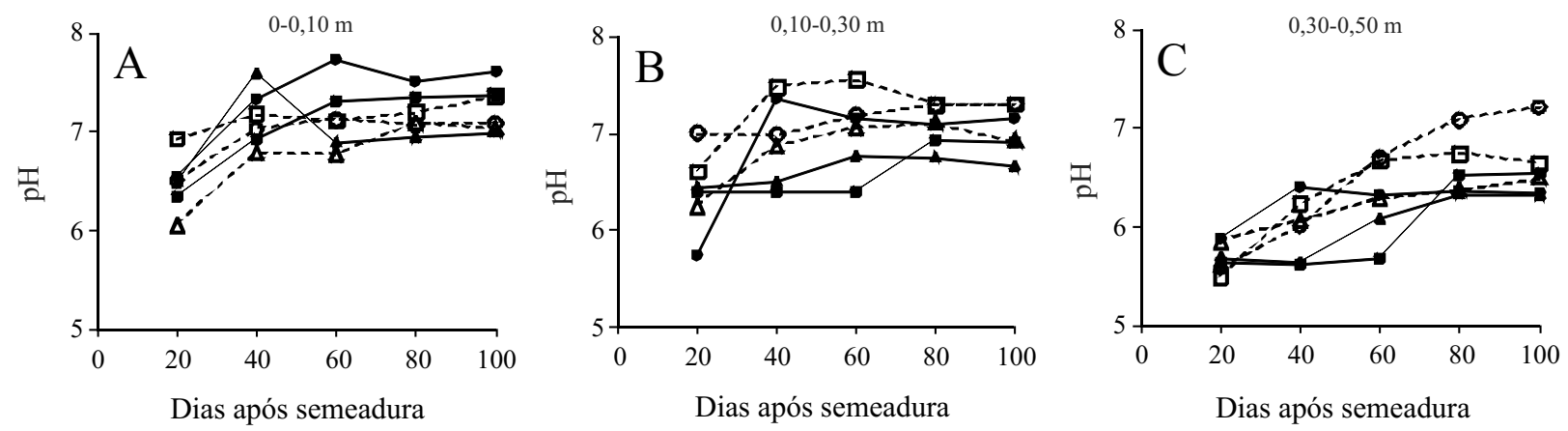

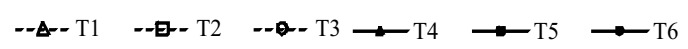

Figura 7 - Evolução do pH em um Argissolo ao longo do ciclo do girassol em função dos tratamentos em cada camada

a sua utilização apenas em alguns estádios das culturas e a mistura de águas de diferentes qualidades, não são suficientes para reduzir a salinização/sodificação do solo. Apesar disso, essas estratégias podem ser usadas com sucesso em alguns casos (CHAUHAN et al., 2008; LACERDA et al., 2009; MALASH et al., 2005; 
MURTAZA et al., 2006; NEVES et al., 2008), desde que sejam adotadas práticas para evitar o aumento gradual da salinidade/sodicidade do solo.

$\mathrm{O}$ aumento acentuado do $\mathrm{Na}^{+}$nos tratamentos que receberamaságuas $\mathrm{S} 2 \mathrm{eS} 3$ pode seratribuídoà característica dessas águas, pois as mesmas possuíam elevados teores do íon $\mathrm{Na}^{+}$na sua composição (TAB. 3). No caso da água S3 os sais $\mathrm{NaCl}$ e $\mathrm{NaHCO}_{3}$ representavam $67,19 \%$ do total adicionado na água $\mathrm{S} 1$. Vale lembrar que a predominância dessa espécie iônica no meio de crescimento, além de causar toxidez quando se acumula nos tecidos vegetais, pode acarretar mudanças na capacidade das plantas em absorver, transportar e utilizar os íons essenciais ao seu crescimento (LACERDA et al., 2004). Além disso, o aumento do $\mathrm{Na}^{+}$também é responsável pela degradação da estrutura do solo, reduzindo a infiltração de água.
No que diz respeito ao aumento da CE nos tratamentos que receberam as águas S2 e S3, ainda não foi suficiente para classificar o solo como salino segundo Richards (1954). Entretanto, nessas condições, já seria recomendável a aplicação de lâminas de água para lixiviar o excesso de sais, visto que as precipitações pluviais na região Nordeste podem ser insuficientes para proporcionar essa lixiviação.

Em relação ao aumento do $\mathrm{pH}$, provavelmente está relacionado aos elevados teores de carbonato e bicarbonato da água de irrigação (TAB. 3). Essa alteração do $\mathrm{pH}$ é relevante, pois o mesmo influencia a solubilidade dos elementos essenciais e tóxicos existentes no solo e a atividade e diversidade de microrganismos do solo (CHAVES et al., 2006).

Tabela 6 - Resumo da ANOVA para sódio trocável, $\mathrm{Na}^{+} / \mathrm{Ca}^{2+}, \mathrm{Na}^{+} / \mathrm{Mg}^{2+}, \mathrm{CE}$ e pH aos 100 DAS nas camadas 0-0,10;0,10-0,30; 0,30-0,50 m, em função dos tratamentos

\begin{tabular}{|c|c|c|c|c|c|c|}
\hline \multirow{3}{*}{ Fonte de variação } & \multirow{3}{*}{ GL } & \multicolumn{5}{|c|}{ Camada 0-0,10 m } \\
\hline & & \multicolumn{5}{|c|}{ Quadrado médio } \\
\hline & & $\mathrm{Na}^{+}$ & $\mathrm{Na}^{+} / \mathrm{Ca}^{2+}$ & $\mathrm{Na}^{+} / \mathrm{Mg}^{2+}$ & $\mathrm{CE}$ & $\mathrm{pH}$ \\
\hline Tratamentos & 5 & $1,490742 * *$ & $0,223354 * *$ & $0,275446^{* *}$ & $0,104029 * *$ & $0,311033^{* *}$ \\
\hline Blocos & 4 & 0,046564 & 0,006219 & 0,009722 & 0,013535 & 0,054722 \\
\hline Resíduo & 20 & 0,036364 & 0,038761 & 0,054532 & 0,011652 & 0,074339 \\
\hline \multirow{2}{*}{ C. V. $(\%)$} & - & 8,42 & 20,57 & 19,42 & 15,28 & 3,76 \\
\hline & & \multicolumn{5}{|c|}{ Camada $0,10-0,30 \mathrm{~m}$} \\
\hline \multirow[t]{2}{*}{ Fonte de variação } & GL & \multicolumn{5}{|c|}{ Quadrado médio } \\
\hline & & $\mathrm{Na}^{+}$ & $\mathrm{Na}^{+} / \mathrm{Ca}^{2+}$ & $\mathrm{Na}^{+} / \mathrm{Mg}^{2+}$ & $\mathrm{CE}$ & $\mathrm{pH}$ \\
\hline Tratamentos & 5 & $1,481592 * *$ & $0,215811 * *$ & $0,236627 * *$ & $0,139493 * *$ & $0,319735^{* *}$ \\
\hline Blocos & 4 & 0,123363 & 0,026366 & 0,038226 & 0,004173 & 0,164847 \\
\hline Resíduo & 20 & 0,118068 & 0,022261 & 0,047412 & 0,002359 & 0,079365 \\
\hline C. V. $(\%)$ & - & 15,48 & 15,69 & 18,09 & 7,12 & 4,00 \\
\hline \multirow{3}{*}{ Fonte de variação } & \multirow{3}{*}{ GL } & \multicolumn{5}{|c|}{ Camada 0,30-0,50 m } \\
\hline & & \multicolumn{5}{|c|}{ Quadrado médio } \\
\hline & & $\mathrm{Na}^{+}$ & $\mathrm{Na}^{+} / \mathrm{Ca}^{2+}$ & $\mathrm{Na}^{+} / \mathrm{Mg}^{2+}$ & $\mathrm{CE}$ & $\mathrm{pH}$ \\
\hline Tratamentos & 5 & $1,767493 * *$ & $0,310211 * *$ & $0,459818 * *$ & $0,110585 * *$ & $0,528331 * *$ \\
\hline Blocos & 4 & 0,092561 & 0,038338 & 0,015087 & 0,007190 & 0,103483 \\
\hline Resíduo & 20 & 0,156600 & 0,037367 & 0,082631 & 0,004707 & 0,087491 \\
\hline C. V. $(\%)$ & - & 17,87 & 19,36 & 23,43 & 10,44 & 4,49 \\
\hline
\end{tabular}

** - Significativo $(\mathrm{p}<0,01)$ pelo teste $\mathrm{F}$ 
Tabela 7 - Médias de sódio trocável, $\mathrm{Na}^{+} / \mathrm{Ca}^{2+}, \mathrm{Na}^{+} / \mathrm{Mg}^{2+}, \mathrm{CE}$ e pH aos 100 DAS nas camadas 0-0,10;0,10-0,30;0,30-0,50 m, em função dos tratamentos

\begin{tabular}{|c|c|c|c|}
\hline \multirow{3}{*}{ Tratamentos } & \multicolumn{3}{|c|}{ Atributos químicos do solo } \\
\hline & \multicolumn{3}{|c|}{$\mathrm{Na}^{+}\left(\mathrm{mmol}_{\mathrm{c}} \mathrm{dm}^{-3}\right)$} \\
\hline & $0-0,10 \mathrm{~m}$ & $0,10-0,30 \mathrm{~m}$ & $0,30-0,50 \mathrm{~m}$ \\
\hline $\mathrm{T} 1$ & $3,29 \mathrm{~b}$ & $3,19 b$ & $3,11 \mathrm{~b}$ \\
\hline $\mathrm{T} 2$ & $13,74 \mathrm{a}$ & $12,56 \mathrm{a}$ & $11,90 \mathrm{a}$ \\
\hline $\mathrm{T} 3$ & $13,76 \mathrm{a}$ & 13,79 a & 15,66 a \\
\hline $\mathrm{T} 4$ & $9,73 \mathrm{a}$ & $10,05 \mathrm{a}$ & $8,94 \mathrm{a}$ \\
\hline $\mathrm{T} 5$ & $12,30 \mathrm{a}$ & $12,23 \mathrm{a}$ & $13,69 \mathrm{a}$ \\
\hline T6 & $11,78 \mathrm{a}$ & $11,69 \mathrm{a}$ & $11,29 \mathrm{a}$ \\
\hline \multirow{2}{*}{ Tratamentos } & \multicolumn{3}{|c|}{$\mathrm{Na}^{+} / \mathrm{Ca}^{2+}$} \\
\hline & $0-0,10 \mathrm{~m}$ & $0,10-0,30 \mathrm{~m}$ & $0,30-0,50 \mathrm{~m}$ \\
\hline $\mathrm{T} 1$ & $0,2836 \mathrm{~b}$ & $0,2845 \mathrm{~b}$ & $0,3367 \mathrm{~b}$ \\
\hline $\mathrm{T} 2$ & $1,1083 \mathrm{a}$ & $1,1212 \mathrm{a}$ & $1,1665 \mathrm{a}$ \\
\hline $\mathrm{T} 3$ & $1,2742 \mathrm{a}$ & $1,2768 \mathrm{a}$ & $1,5658 \mathrm{a}$ \\
\hline $\mathrm{T} 4$ & $0,8844 \mathrm{a}$ & $0,8816 \mathrm{a}$ & $0,7846 \mathrm{ab}$ \\
\hline $\mathrm{T} 5$ & $1,0787 \mathrm{a}$ & $1,0362 \mathrm{a}$ & $1,3692 \mathrm{a}$ \\
\hline T6 & $1,0707 \mathrm{a}$ & $1,0628 \mathrm{a}$ & $0,9821 \mathrm{a}$ \\
\hline \multirow{2}{*}{ Tratamentos } & \multicolumn{3}{|c|}{$\mathrm{Na}^{+} / \mathrm{Mg}^{2+}$} \\
\hline & $0-0,10 \mathrm{~m}$ & $0,10-0,30 \mathrm{~m}$ & $0,30-0,50 \mathrm{~m}$ \\
\hline $\mathrm{T} 1$ & $0,5672 \mathrm{~b}$ & $0,5493 \mathrm{~b}$ & $0,5190 \mathrm{~b}$ \\
\hline $\mathrm{T} 2$ & 1,8749 a & $1,7940 \mathrm{a}$ & $1,6998 \mathrm{a}$ \\
\hline $\mathrm{T} 3$ & $1,7643 \mathrm{a}$ & $1,7793 \mathrm{a}$ & $2,5255 \mathrm{a}$ \\
\hline $\mathrm{T} 4$ & $1,2472 \mathrm{ab}$ & $1,4357 \mathrm{a}$ & $1,1769 \mathrm{ab}$ \\
\hline $\mathrm{T} 5$ & $1,7079 \mathrm{a}$ & $1,6866 \mathrm{a}$ & $1,9561 \mathrm{a}$ \\
\hline $\mathrm{T} 6$ & $1,8845 \mathrm{a}$ & $1,7527 \mathrm{a}$ & $1,5263 \mathrm{a}$ \\
\hline \multirow{2}{*}{ Tratamentos } & \multicolumn{3}{|c|}{$\mathrm{CE}\left(\mathrm{dS} \mathrm{m} \mathrm{m}^{-1}\right)$} \\
\hline & $0-0,10 \mathrm{~m}$ & $0,10-0,30 \mathrm{~m}$ & $0,30-0,50 \mathrm{~m}$ \\
\hline $\mathrm{T} 1$ & $0,18 \mathrm{~b}$ & $0,16 \mathrm{e}$ & $0,14 \mathrm{c}$ \\
\hline $\mathrm{T} 2$ & $0,64 \mathrm{a}$ & $0,54 \mathrm{bc}$ & $0,50 \mathrm{ab}$ \\
\hline $\mathrm{T} 3$ & $0,69 \mathrm{a}$ & $0,72 \mathrm{a}$ & $0,67 \mathrm{a}$ \\
\hline $\mathrm{T} 4$ & $0,50 \mathrm{a}$ & $0,51 \mathrm{c}$ & $0,42 \mathrm{~b}$ \\
\hline $\mathrm{T} 5$ & $0,55 \mathrm{a}$ & $0,35 \mathrm{~d}$ & $0,45 \mathrm{~b}$ \\
\hline T6 & $0,59 \mathrm{a}$ & $0,66 \mathrm{ab}$ & $0,54 \mathrm{ab}$ \\
\hline \multirow{2}{*}{ Tratamentos } & \multicolumn{3}{|c|}{$\mathrm{pH}\left(\mathrm{H}_{2} \mathrm{O}\right)$} \\
\hline & $0-0,10 \mathrm{~m}$ & $0,10-0,30 \mathrm{~m}$ & $0,30-0,50 \mathrm{~m}$ \\
\hline $\mathrm{T} 1$ & $7,03 \mathrm{~b}$ & $6,92 \mathrm{ab}$ & $6,49 \mathrm{~b}$ \\
\hline $\mathrm{T} 2$ & $7,36 \mathrm{ab}$ & $7,30 \mathrm{a}$ & $6,64 \mathrm{ab}$ \\
\hline $\mathrm{T} 3$ & $7,08 \mathrm{ab}$ & $7,30 \mathrm{a}$ & $7,21 \mathrm{a}$ \\
\hline $\mathrm{T} 4$ & $6,99 \mathrm{~b}$ & $6,66 \mathrm{~b}$ & $6,32 \mathrm{~b}$ \\
\hline $\mathrm{T} 5$ & $7,38 \mathrm{ab}$ & $6,91 \mathrm{ab}$ & $6,55 \mathrm{~b}$ \\
\hline T6 & $7,62 \mathrm{a}$ & $7,15 \mathrm{ab}$ & $6,35 \mathrm{~b}$ \\
\hline
\end{tabular}

Médias seguidas da mesma letra na coluna, não diferem significativamente entre si (Tukey, $p<0,05)$ 


\section{Conclusões}

1. A cultura do girassol mostrou-se tolerante à salinidade da água de irrigação, indicando que ela pode ser irrigada com água de $\mathrm{CE}$ de até $3,53 \mathrm{dS} \mathrm{m}^{-1}$ durante todo o ciclo. Entretanto, quando se utilizar água de média ou alta $\mathrm{CE}$, é necessária a adoção de práticas de controle da salinização/sodificação do solo;

2. A tolerância do girassol à salinidade não dependeu da fase de desenvolvimento;

3. Em geral, os atributos químicos do solo aumentaram e estabilizaram a partir da metade do ciclo.

\section{Agradecimentos}

Os autores agradecem ao $\mathrm{CNPq}$ pelo apoio na realização dessa pesquisa, mediante a liberação de auxílios financeiros provenientes do "Projeto Casadinho" entre a UFERSA e a UFRRJ e do Instituto Nacional de Ciência e Tecnologia em Salinidade (INCTSal).

\section{Referências}

ASHRAF, M.; TUFAIL, M. Variation in salinity tolerance in sunflower (Helianthus annuus L.). Journal of Agronomy and Crop Science, v. 174, n. 05, p. 351-362, 1995.

BANZATTO, D. A.; KRONKA, S. N. Experimentação agrícola. 3. ed. Jaboticabal: FUNEP, 1995. 247 p.

BHATT, J. G.; INDIRAKUTTY, K. N. Salt uptake and salt tolerance by sunflower. Plant and Soil, v. 39, n. 02, p. 457-460, 1973.

BLANCO, F. F. et al. Emergence and growth of corn and soybean under saline stress. Scientia Agricola, v. 64, n. 05, p. 451-459, 2007.

CARMO FILHO, F.; ESPÍNOLA SOBRINHO, J.; MAIA NETO, J. M. Dados climatológicos de Mossoró: um município semi-árido nordestino. Mossoró: ESAM, 1991. 121 p. (Coleção Mossoroense, série C, 30)

CASTIGLIONI, V. B. R. et al. Fases de desenvolvimento da planta de girassol. Londrina: EMBRAPA-CNPSo, 1997. 24 p.

CHAUHAN, C.P. S.; SINGH, R. B.; GUPTA, S. K. Supplemental irrigation of wheat with saline water. Agricultural Water Management, v. 95, n. 03, p. 253-258, 2008.

CHAVES, L. H. G. et al. Variabilidade de propriedades químicas do solo aluvial da Ilha de Picos, Pernambuco. Revista de Biologia e Ciências da Terra, v. 6, n. 01, p. 13-19, 2006.

CONAB. Companhia Nacional de Abastecimento. Acompanhamento da safra brasileira: grãos - safra 2009/2010. Brasília: Conab, 2010. 42 p. (Nono Levantamento).

CORREIA, K. G. et al. Crescimento, produção e características de fluorescência da clorofila a em amendoim sob condições de salinidade. Revista Ciência Agronômica, v. 40, n. 04, p. 514-521, 2009

DIAS, N. S. et al. Evolução da salinidade em um argissolo sob cultivo de melão irrigado por gotejamento. Revista Brasileira de Engenharia Agrícola e Ambiental, v. 8, n. 02/03, p. 240-246, 2004.
EMBRAPA. Centro Nacional de Pesquisa de Solos. Sistema brasileiro de classificação de solos. Brasília: Embrapa Produção da Informação; Rio de Janeiro: Embrapa Solos, 1999. 412 p.

FERREIRA, D. F. SISVAR: um programa para análises e ensino de estatística. Revista Científica Symposium, v. 6, n. 02 , p. $36-41,2008$

KATERJI, N. et al. Salt tolerance classification of crops according to soil salinity and to water stress day index. Agricultural Water Management, v. 43, n. 01, p. 99-109, 2000.

LACERDA, C. F. et al. Influência do cálcio sobre o crescimento e solutos em plântulas de sorgo estressadas com cloreto de sódio. Revista Brasileira de Ciência do Solo, v. 28, n. 02, p. 289-295, 2004.

LACERDA, C. F. et al. Eficiência de utilização de água e nutrientes em plantas de feijão-de-corda irrigadas com água salina em diferentes estádios de desenvolvimento. Engenharia Agrícola, v. 29, n. 02, p. 221-230, 2009.

$\mathrm{LV}$, S. et al. Overexpression of an $\mathrm{H}^{+}-\mathrm{PPase}$ gene from Thellungiella halophila in cotton enhances salt tolerance and improves growth and photosynthetic performance. Plant \& Cell Physiology, v. 49, n. 08, p. 1150-1164, 2008.

MALASH, N.; FLOWERS, T. J.; RAGAB, R. Effect of irrigation systems and water management practices using saline and non-saline water on tomato production. Agricultural Water Management, v. 78, n. 01/02, p. 25-38, 2005.

MEDEIROS, J. F. Qualidade da água de irrigação e evolução da salinidade nas propriedades assistidas pelo GAT nos Estados do RN, PB e CE. 1992. 173 f. Dissertação (Mestrado em Engenharia Agrícola) - Universidade Federal da Paraíba, Campina Grande.

MURTAZA, G.; GHAFOOR, A.; QADIR, M. Irrigation and soil management strategies for using saline-sodic water in a cotton-wheat rotation. Agricultural Water Management, v. 81, n. 01/02, p. 98-114, 2006.

NEVES, A. L. R. et al. Tamanho e composição mineral de sementes de feijão-de-corda irrigado com água salina. Revista Ciência Agronômica, v. 39, n. 04, p. 569-574, 2008.

NOBRE, R. G. et al. Crescimento e floração do girassol sob estresse salino e adubação nitrogenada. Revista Ciência Agronômica, v. 41, n. 03, p. 358-365, 2010

RICHARDS, L. A. (Ed.) Diagnosis and improvement of saline and alkali soils. Washington: US Department of Agriculture, 1954. 160 p. (USDA Agricultural Handbook, 60).

SILVA, E. N. et al. Acúmulo de íons e crescimento de pinhãomanso sob diferentes níveis de salinidade. Revista Ciência Agronômica, v. 40, n. 02, p. 240-246, 2009.

SILVA, F. C. (Ed.) Manual de análises químicas de solos, plantas e fertilizantes. 2. ed. Brasília: Embrapa Informação Tecnológica; Rio de Janeiro: Embrapa Solos, 2009. 627 p.

SILVA, M. L. O. E. et al. Viabilidade técnica e econômica do cultivo de safrinha do girassol irrigado na região de Lavras, MG. Ciência e Agrotecnologia, v. 31, n. 01, p. 200-205, 2007.

SILVA, S. M. S. et al. Desenvolvimento e produção de duas cultivares de mamoneira sob estresse salino. Revista Brasileira de Engenharia Agrícola e Ambiental, v. 12, n. 04, p. 335-342, 2008.

SILVA, T. G. F. et al. Crescimento do girassol ornamental cultivado em ambiente protegido sob diferentes níveis de condutividade elétrica de fertirrigação. Revista Ceres, v. 56, n. 05, p. 602-610, 2009.

ZOBIOLE, L. H. S. et al. Marcha de absorção de macronutrientes na cultura do girassol. Revista Brasileira de Ciência do Solo, v. 34, n. 02, p. 425-433, 2010. 